\title{
Fault Orientation Determination for the 4 March 2008 Taoyuan Earthquake from Dense Near-Source Seismic Observations
}

\author{
Min-Hung Shih ${ }^{1,2}$, Bor-Shouh Huang ${ }^{2, *}$, Lupei Zhu ${ }^{3}$, Horng-Yuan Yen ${ }^{1}$, Tao-Ming Chang ${ }^{4}$, \\ Win-Gee Huang ${ }^{2}$, and Chien-Ying Wang ${ }^{1}$ \\ ${ }^{1}$ Institute of Geophysics, National Central University, Taiwan \\ ${ }^{2}$ Institute of Earth Sciences, Academia Sinica, Taiwan \\ ${ }^{3}$ Department of Earth and Atmospheric Sciences, Saint Louis University, USA \\ ${ }^{4}$ National Center for Research on Earthquake Engineering, Taiwan
}

Received 22 April 2014, accepted 19 May 2014

\begin{abstract}
On 4 March 2008, a moderate earthquake $\left(\mathrm{M}_{\mathrm{L}}=5.2\right)$ occurred in southern Taiwan and named as the Taoyuan earthquake, preceded by foreshocks and followed by numerous aftershocks. This earthquake sequence occurred during the TAIGER (TAiwan Integrated GEodynamics Research) controlled-source seismic experiment. Consequently, several seismic networks were deployed in the Taiwan area at this time and many stations recorded this earthquake sequence in the near-source region. We archived and processed near-source observations to determine the fault orientation. To locate the events more accurately, station corrections, waveform cross-correlation to pick seismic phases, and a double-difference earthquake location algorithm were used to compute earthquake hypocenters. Over a 50-hour recording period, beginning half an hour before the start of the main shock, 2340 events were identified within the earthquake sequence. The identified aftershocks reveal a clear fault plane with a strike of $\mathrm{N} 37^{\circ} \mathrm{E}$ and a dip of $45^{\circ} \mathrm{SE}$. This plane corresponds to one of the focal mechanism nodal planes determined by the Broadband Array in Taiwan for Seismology (BATS) ( strike $=37^{\circ}$, dip $=48^{\circ}$, and rake $=96^{\circ}$ ). Based on the main shock focal mechanism, the aftershock distribution, and the regional geological reports, we suggest that faulting on the northern extension of the major regional active fault, the Chishan Fault, caused the Taoyuan earthquake sequence.
\end{abstract}

Key words: Taoyuan earthquake, TAIGER, Aftershocks, Fault orientation

Citation: Shih, M. H., B. S. Huang, L. Zhu, H. Y. Yen, T. M. Chang, W. G. Huang, and C. Y. Wang, 2014: Fault orientation determination for the 4 March 2008 Taoyuan earthquake from dense near-source seismic observations. Terr. Atmos. Ocean. Sci., 25, 637-645, doi: 10.3319/TAO.2014.05.19.01(T)

\section{INTRODUCTION}

On 4 March 2008, at 17:31 (UTC) a moderate earthquake $\left(\mathrm{M}_{\mathrm{L}}\right.$ 5.2) occurred in southern Taiwan near the southwestern part of the Taoyuan District of Kaohsiung City. The earthquake is referred to as the Taoyuan earthquake in this study. A regional seismic network, the Central Weather Bureau Seismic Network (CWBSN), composed of three-component digital short-period seismic stations covering all of the Taiwan area, recorded this earthquake sequence (Fig. 1). This event consisted of a number of foreshocks and numerous aftershocks after the main shock, including three events with magnitudes greater than 4 (Lin 2010). However, the aftershock distribution from the CWBSN revealed insuffi-

\footnotetext{
* Corresponding author

E-mail:hwbs@earth.sinica.edu.tw
}

cient resolution to identify the fault structure. Many small events had computed locations with high uncertainties that were determined using limited near-source stations (Fig. 1). Fortunately, the earthquake sequence occurred during the TAIGER (TAiwan Integrated GEodynamics Research) controlled-source seismic experiment (Okaya et al. 2009). Consequently, several seismic networks were deployed in the Taiwan area at this time to monitor TAIGER explosions and many stations recorded the earthquake sequence at close range.

We archived all available near-source seismic records from this period and processed them together for this study. We employed waveform cross-correlation analysis (Yang et al. 2009) and a double-difference earthquake location algorithm (Waldhauser and Ellsworth 2000) to determine the relative arrival times, improve the event locations and 
examine the rupture plane. The spatial distribution of aftershocks and the attitude of the rupture fault plane were determined from these analyses. The implications of these results for moderate earthquake fault processes and related earthquake source physics are discussed.

\section{DATA}

On 4 March 2008 the TAIGER controlled-source seismic experiment was underway. More than 500 seismometers were deployed on the island of Taiwan to observe the TAIGER explosive sources. The Taoyuan earthquake and its aftershocks were recorded by those seismometers. We collected all available near-source seismic observations of this event from several seismic networks deployed by different institutes (Fig. 1). These networks included: (1) the Broadband Array in Taiwan for Seismology (BATS), a permanent network operated by the Institute of Earth Sciences (IES), Academia Sinica; (2) two portable arrays of broadband instruments deployed by the National Center for Research on Earthquake Engineering (NCREE) and National Chung Cheng University (NCCU); (3) a portable linear array across southern Taiwan with broadband instruments from both the IES and IRIS PASSCAL instrument center deployed during the TAIGER project, named as IES and TAIGER (BB), respectively in Fig. 1; and (4) a temporary array equipped with a RefTek RT-125A (Texan) Datalogger and $4.5 \mathrm{~Hz}$ geophones deployed by the TAIGER project [named as TAIGER (TEXAN) in this study] and distributed at a spacing of $\sim 2 \mathrm{~km}$ in a north-south direction. The nearest seismometer to the epicenter of the main shock was about $2.5 \mathrm{~km}$ away. We processed seismic data from all available near-source stations within the area delimited by latitudes of $23.0^{\circ}$ and $23.5^{\circ} \mathrm{N}$, and longitudes of $120.4^{\circ}$ and $121.0^{\circ} \mathrm{E}$, as shown in Fig. 1.

The seismic instruments were operated in a continuous recording mode. The sampling intervals were $0.004 \mathrm{sec}$ for the Texan instruments and $0.01 \mathrm{sec}$ for all others. All records between 17:00 on 4 March 2008 (half an hour before the main shock) and 20:00 on 6 March 2008 (total duration of 51 hours) were retrieved. The seismic waveforms collected from the dense near-source seismic stations provide highquality data for locating small-magnitude events. However, the large amount of data selected for this study required automated processing. To retrieve additional events from the CWBSN catalog, several automatic data-processing techniques were employed for data picking and event location in this study.

\section{ANALYSIS AND RESULTS}

To process the large amount of digital seismic data,
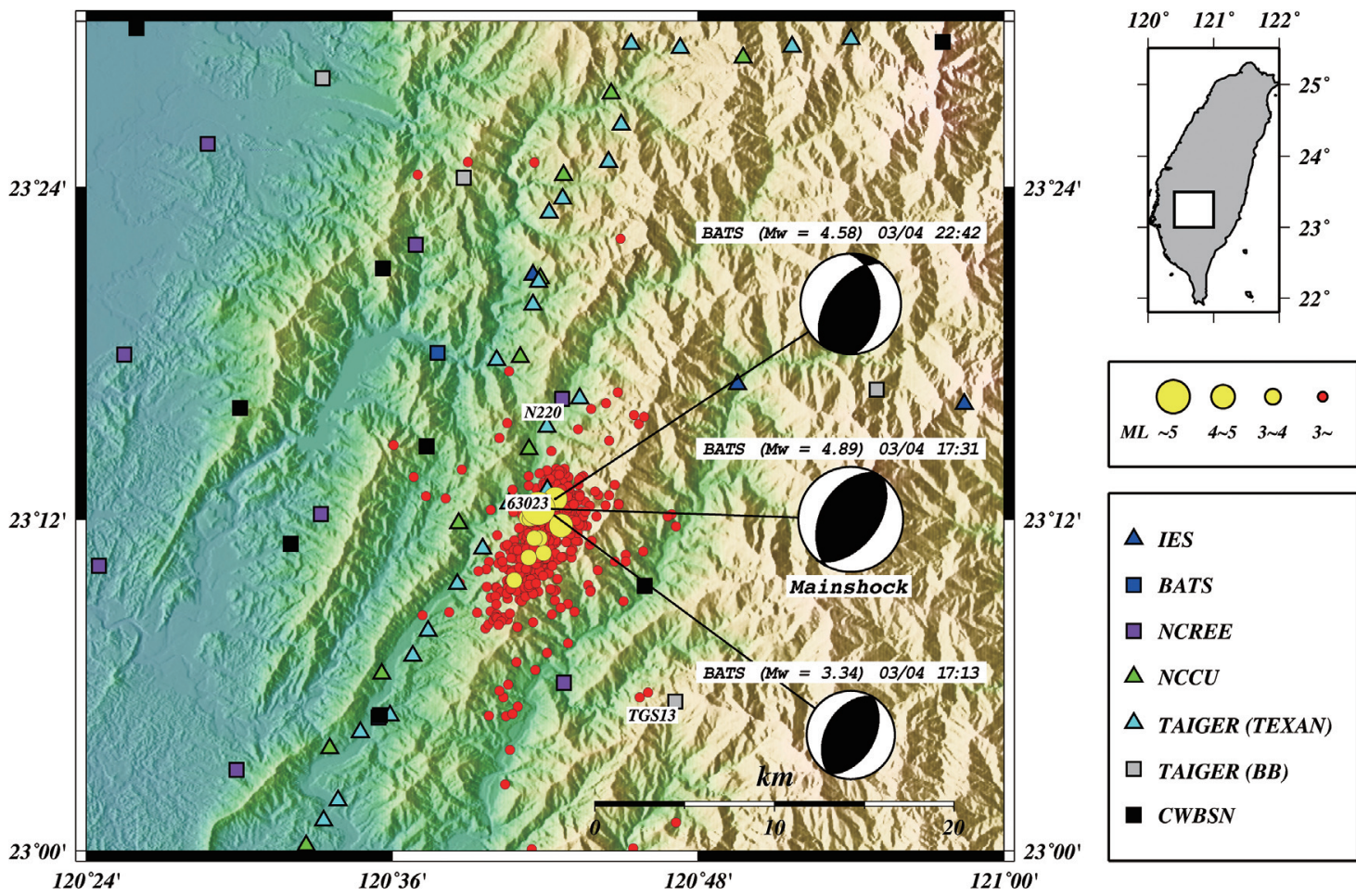

Fig. 1. Seismic events of the 4 March 2008 Taoyuan earthquake sequence reported by the CWBSN, and the locations of seismic stations used in this study. The seismic network names are listed as abbreviations in the symbol legend and their full names can be found in the text. The seismic events are plotted as circles with their sizes corresponding to their magnitudes, as listed in the figure legend. The moment tensor solutions for three major events of this earthquake sequence, determined by BATS, are also shown. 
Antelope software (Antelope User Group 2014) developed by Boulder Real-Time Technologies was employed. This software package provides various tools for data management and analysis. To analyze seismic events, a relational database must first be built within the Antelope system. The database contains both metadata and waveform data. The Antelope package provides a series of routines to identify arrivals, locate hypocenters and relocate events.

The continuous seismic traces were processed using Antelope to identify seismic phases and identify arrival times. Preliminary event locations were easily determined using a single event method of least-squared residuals (Lee and Lahr 1975; Klein 1978; Lahr 1989) using a 1-D velocity structure derived from Chen (1995). The velocity structure is shown in Table 1. After preliminary processing, 2340 events were identified within a 51-hour data window that began half an hour before the onset of the main shock (Fig. 2a). The time uncertainties were manually examined for each seismic phase. The estimated uncertainties ranged from $0.01-0.5 \mathrm{sec}$ for P-wave arrivals and $0.05-0.8 \mathrm{sec}$ for S-wave arrivals. Each arrival was weighted based on its uncertainty and hypocenter distance. The station corrections

Table 1. 1-D velocity model used for this study.

\begin{tabular}{cc}
\hline Depth $(\mathbf{k m})$ & P-wave velocity $\left(\mathbf{k m ~ s e c} \mathbf{~}^{-1}\right)$ \\
\hline 0 & 3.52 \\
2 & 4.42 \\
4 & 5.20 \\
9 & 5.81 \\
13 & 6.14 \\
17 & 6.4 \\
25 & 6.88 \\
30 & 7.29 \\
35 & 7.70 \\
\hline
\end{tabular}

(a) $120.65^{\circ} \quad 120.7^{\circ} \quad 120.75^{\circ}$
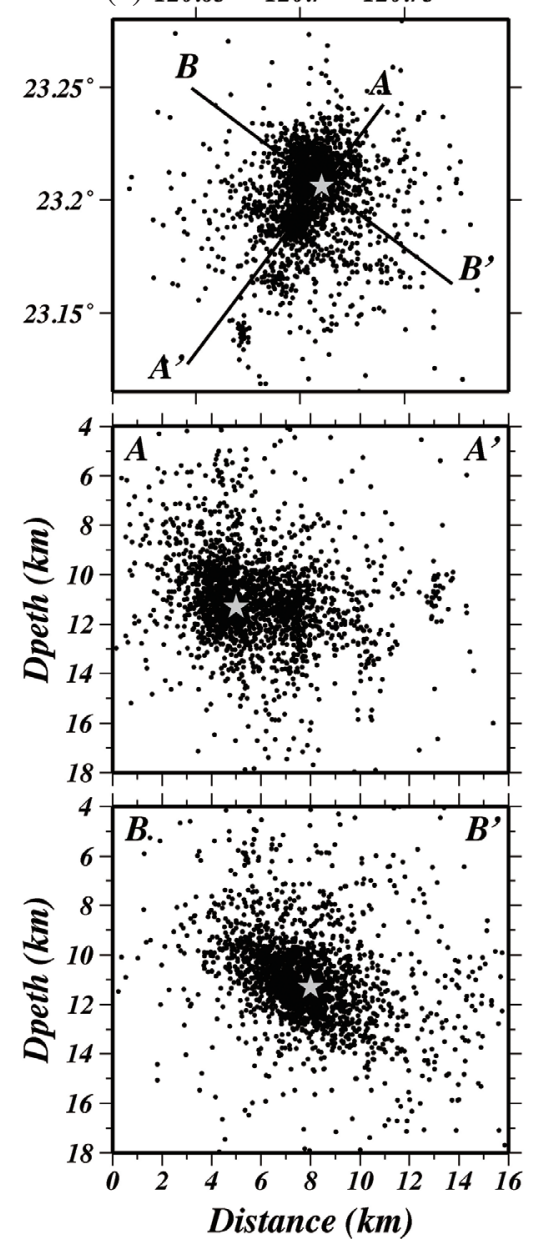

(b) $120.65^{\circ} \quad 120.7^{\circ} \quad 120.75^{\circ}$
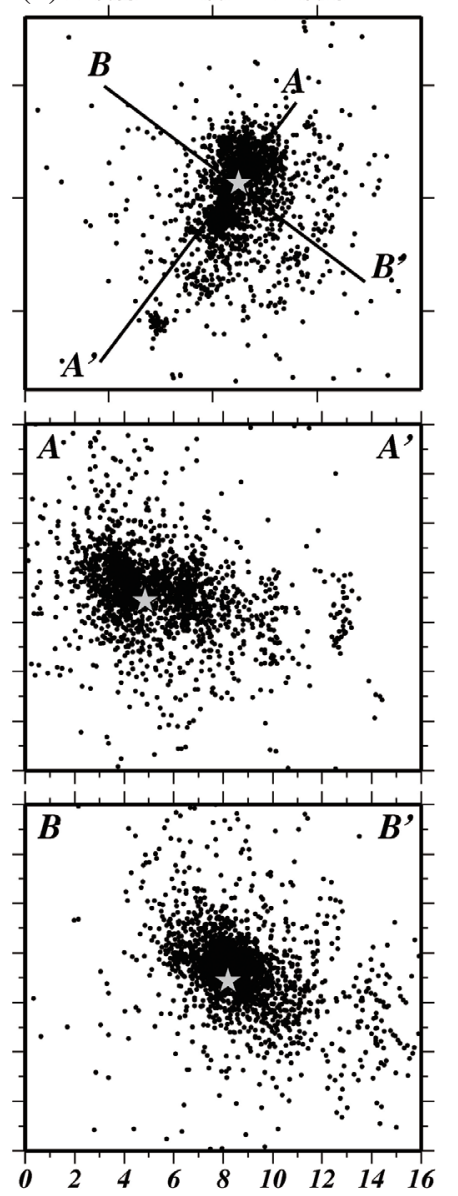

Distance $(\mathrm{km})$ (c) $120.65^{\circ} \quad 120.7^{\circ} \quad 120.75^{\circ}$
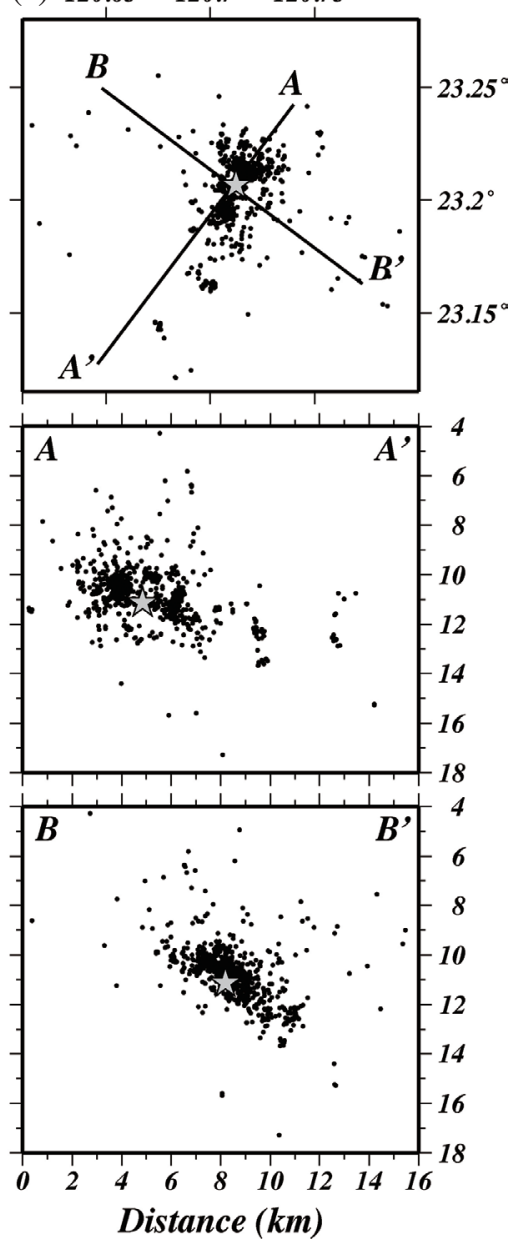

Fig. 2. Relocated hypocenters of the earthquake sequence from (a) the preliminary catalog obtained using Antelope, (b) the revised catalog from Antelope using station corrections, and (c) the relocated catalog obtained from the hypoDD algorithm. The event distributions are shown in map view (first row) and two cross-sections. The cross-sections A - A' (second row) and B - B' (third row) show the vertical planes in the N37 ${ }^{\circ} \mathrm{E}$ and $\mathrm{N} 53^{\circ} \mathrm{W}$ directions, respectively. The star symbol indicates the main shock hypocenter on each panel. 
were calculated using the average value of all travel time residuals at each station. The station corrections were used to relocate the preliminary events as shown in Fig. $2 b$.

Located events were examined using the relative earthquake relocation technique (Waldhauser and Ellsworth 2000) to improve their relative spatial locations. Relocated hypocenters with the following criteria were examined: (1) the number of both $\mathrm{P}$ and $\mathrm{S}$ arrival time readings are greater than or equal to $8,(2)$ event location uncertainties on both horizontal and vertical components are smaller than $1 \mathrm{~km}$, and (3) the event origin time error is less than $1 \mathrm{sec}$.

The differential arrival times were further evaluated using waveform cross-correlation analysis of selected events. The cross-correlation measurements were conducted using a velocity waveform with a $1.0 \mathrm{sec}$ time window and a $1-15 \mathrm{~Hz}$ band-pass filter. In this study, clustered events were selected for further analysis if their normalized cross-correlation coefficient for the seismic waveform was larger than 0.85. Finally, after removal of poorly linked events, 990 events were successfully relocated and clustered in several groups (Fig. 2c). The clustered events have similar waveforms, which may indicate that the events are close in space and may have similar focal mechanisms (Fig. 3).

Figure 2 shows map views and two cross-sections of the located events, as obtained over three steps. Two vertical cross-sections were selected to present the fault orientation of the 4 March 2008 Taoyuan earthquake sequence. Figure 2a shows the 2340 events from the preliminary catalog ob- tained using Antelope software. Figure $2 b$ shows the same events relocated using Antelope software with the inclusion of station corrections. Figure 2c shows the relocated events using the double-difference algorithm (named hypoDD in this study) proposed by Waldhauser and Ellsworth (2000). The A - A' cross-section in the second row of each column is oriented in the $\mathrm{N} 37^{\circ} \mathrm{E}-\mathrm{S} 37^{\circ} \mathrm{W}$ direction, which corresponds with one of the fault strike directions from the main shock focal mechanism determined by BATS (Fig. 1). The B - B' cross-section, in the third row of each column, is oriented perpendicular to the A - A' cross-section and in the $\mathrm{N} 53^{\circ} \mathrm{W}-\mathrm{S} 53^{\circ} \mathrm{E}$ direction.

Shown in Fig. 2, all located events show cloud patterns around the main shock. Aftershock locations extend approximately NE on the map view. In Fig. 2a, on the map view, aftershock locations extend along the $\mathrm{N} 20^{\circ} \mathrm{E}$ direction between $120.68^{\circ}$ and $120.73^{\circ} \mathrm{N}$. On the A - A' cross-section, seismicity is concentrated in a rectangular area extending 2 - $8 \mathrm{~km}$ horizontally and $9-14 \mathrm{~km}$ in depth. For the B - B' cross-section, seismicity is focused between $4-10 \mathrm{~km}$ horizontally and between $8-14 \mathrm{~km}$ in depth. Figure $2 \mathrm{~b}$ shows the same events relocated using Antelope software based on the computed station corrections. The relocated locations provide an improved image of the main shock rupture plane. On the map view, the aftershocks are concentrated along the $\mathrm{N} 30^{\circ} \mathrm{E}$ direction. Compared with Fig. 2a the seismicity is shifted to the east. Events plotted on the A - A' cross-section are divided by the main shock into two major groups on the (a)

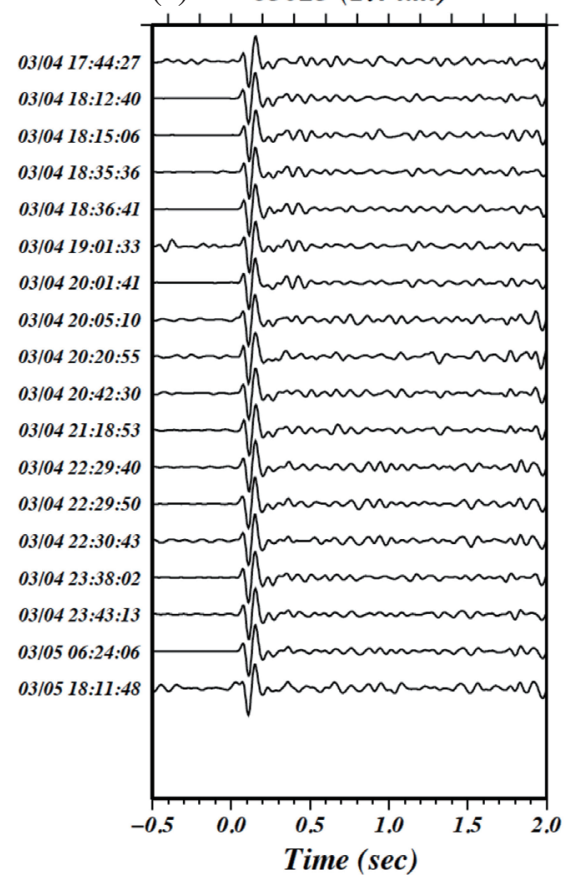

(b)

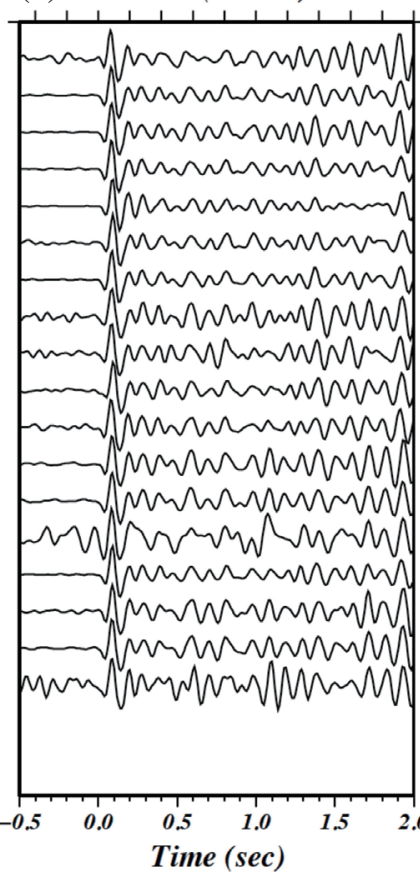

(c) TGS13 $(13.5 \mathrm{~km})$

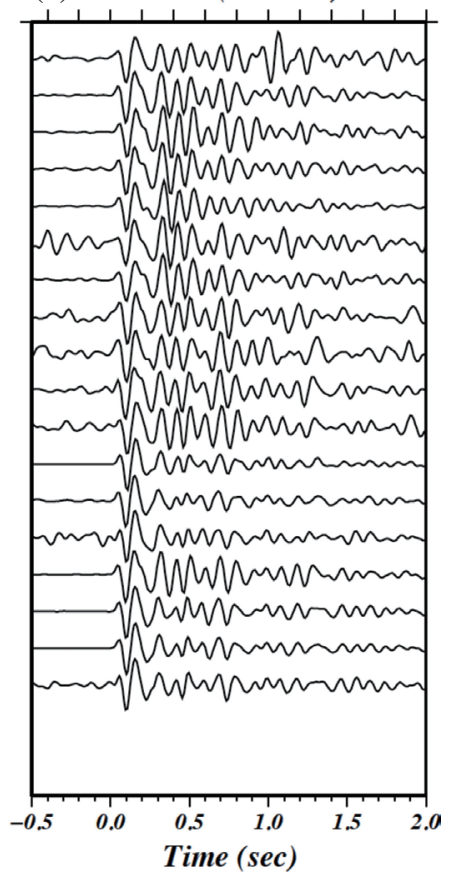

Fig. 3. Aligned vertical-component velocity records for the Taoyuan earthquake sequence recorded at stations (a) 63023, (b) N220, and (c) TGD13. The distance between the main shock epicenter and each station is listed beside the station name. Locations of the three selected stations are shown in Fig. 1. Events are ordered in time with the event origin time listed on the left of the seismic trace panels. 
left and right hand sides of the figure. Based on the B - B' cross-section, aftershocks are estimated to have occurred on an approximately $45^{\circ} \mathrm{SE}$ dipping plane with a depth range between $8-13 \mathrm{~km}$. Figure $2 \mathrm{c}$ shows the events that were relocated using the hypoDD algorithm. Relocated aftershocks show a dense spatial cluster. The aftershocks delineate a clear fault strike of $\mathrm{N} 37^{\circ} \mathrm{E}$ on the map view and a dip of $\sim 45^{\circ} \mathrm{SE}$, ranging in depth between $9-13 \mathrm{~km}$ on the B - B' cross-section. The A - A' cross-section shows a clear fault plane with two major groups of cluster events (left and right hand sides of the main shock in the figure) and a seismic gap beneath the hypocenter of the main shock.

For comparison, we selected the aftershock sequence reported by the CWBSN catalog in the same region as shown in Fig. 2 and for the same time period (a 51-hour data win- dow beginning half an hour before the main shock onset). During this period, 754 events were located by the CWBSN in this region. Despite limited near-source stations (Fig. 1), the number of events determined by the CWBSN is only slightly smaller than the number of events (990 events) determined using the hypoDD algorithm in this study. Figure 4 shows both event distributions reported by (a) the CWBSN and (b) the hypoDD algorithm for this region. In this figure, both the map views and two cross-sections are plotted using the same parameters used in Fig. 2. However, there is a significant difference in the event distributions between the CWBSN and the hypoDD catalogs. Compared with the hypoDD locations, the resolved epicenters from the CWNSN catalog are systematically shifted $1 \mathrm{~km}$ to the NW. For the along-strike direction (A - A'), the plotted event distribution

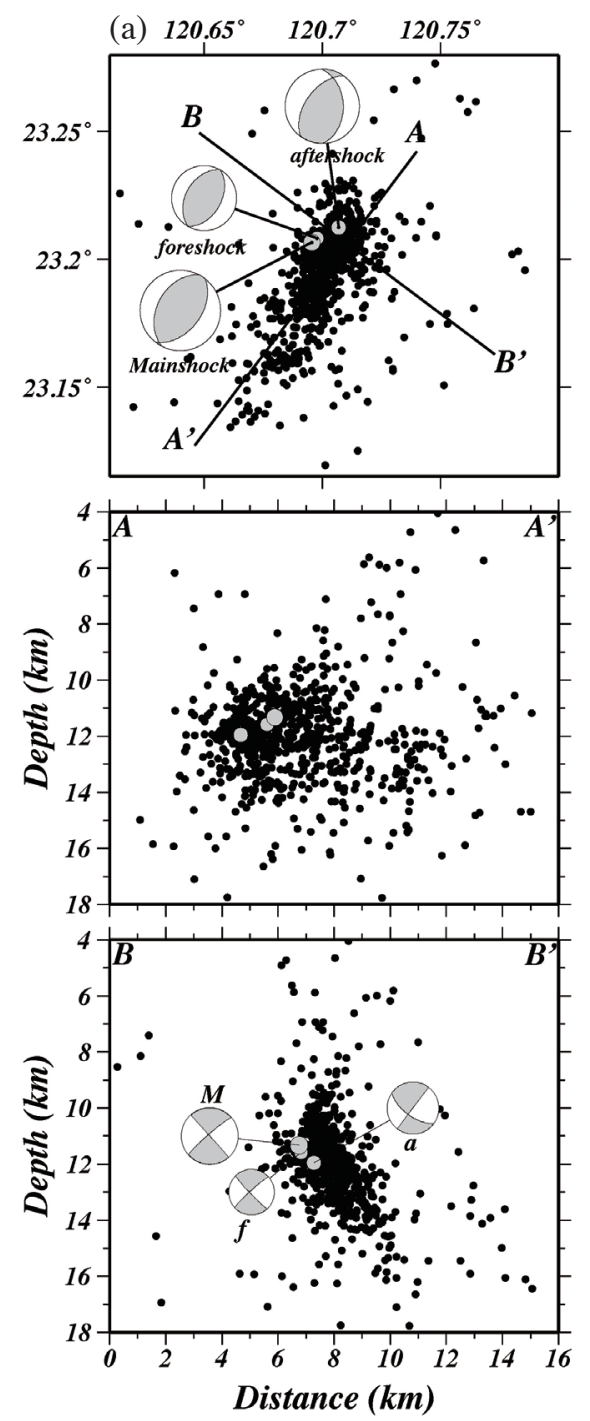

(b) $120.65^{\circ} \quad 120.7^{\circ} \quad 120.75^{\circ}$
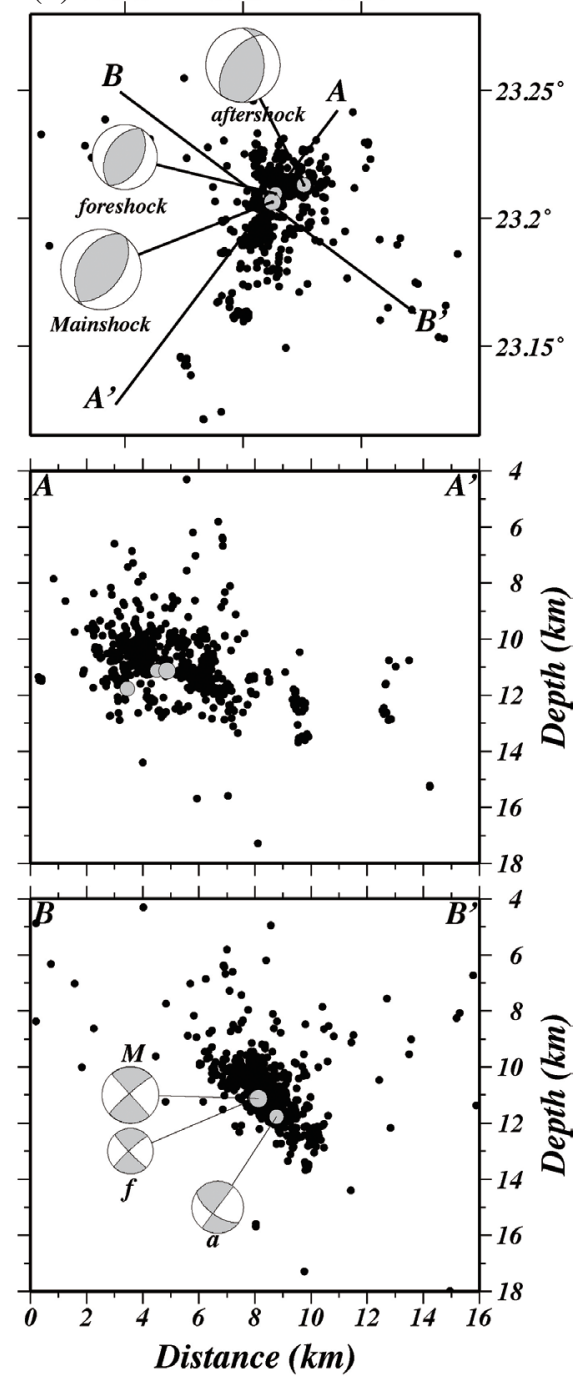

Fig. 4. Map view and cross-section views of relocated hypocenters of the earthquake sequence from (a) the CWBSN catalog and (b) the relocated catalog using the hypoDD algorithm. For the bottom plots, the gray circles indicate the locations of the largest foreshock (f), the main shock (M), and the largest aftershock (a) of this earthquake sequence. The moment tensor solutions for the three major events determined by BATS are also shown. The plot parameters for the cross-sections are the same as in Fig. 2. For cross-section B - B', focal mechanisms are plotted relative to the side view. Locations of the three major events plotted in Fig. $4 \mathrm{~b}$ have been relocated using the hypoDD algorithm. 
from the CWBSN catalog is more scattered than that from the hypoDD catalog. No clear relationship exists between the major events and the aftershocks from the CWBSN catalog (Fig. 4a). However, the aftershocks show clear spatial groups from the hypoDD catalog (Fig. 4b). The region beneath the main shock hypocenter also shows a seismic gap of aftershocks. Figure 4 includes the focal mechanisms of three major events within this earthquake sequence from BATS. Based on the aftershock distribution the fault plane appears to dip southeast, as observed for one nodal plane of the BATS focal mechanisms. Along the B - B' profile, the major events are located within the aftershock cloud from the CWBSN catalog. However, the aftershocks are systematically located on the hanging wall side of the main shock fault plane according to the hypoDD catalog. The angle of dip plane computed from the hypoDD algorithm is slightly smaller than that from the CWBSN.

(a)
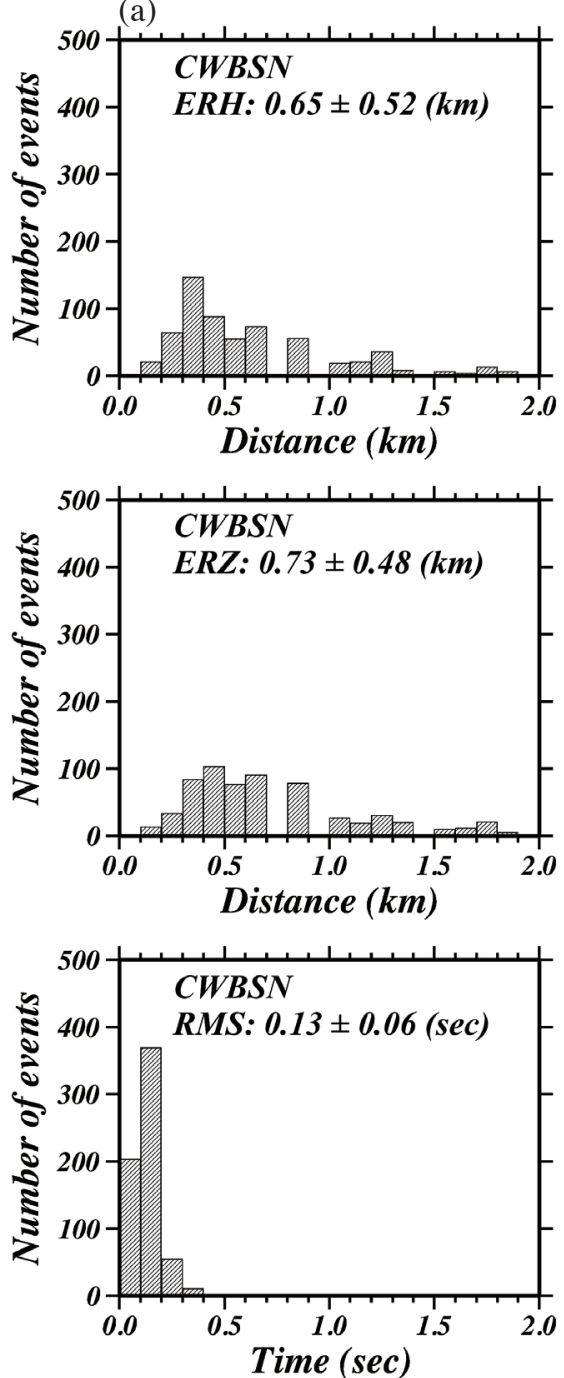

\section{DISCUSSION}

The aftershock distribution is widely used to identify the main shock rupture plane. Previous studies have extracted details of the primary (main shock) and secondary fault structures based on how precisely the aftershocks are located (Liu et al. 2003; Bannister et al. 2006). To estimate CWBSN the location accuracy and that of the dense near-source array used in this study, three error estimates were used: (1) the error in the horizontal distance (ERH), (2) the error in depth (ERZ), and (3) the root-mean-square (RMS) of the travel time residuals (Flinn 1965; Lee and Lahr 1975). Figure 5 shows histograms of the three error estimates for the CWBSN and for the preliminary catalog obtained using Antelope software. Figures 5a and b show the error estimates for the CWBSN and Antelope catalogs, respectively. The estimated average values for ERH, ERZ,
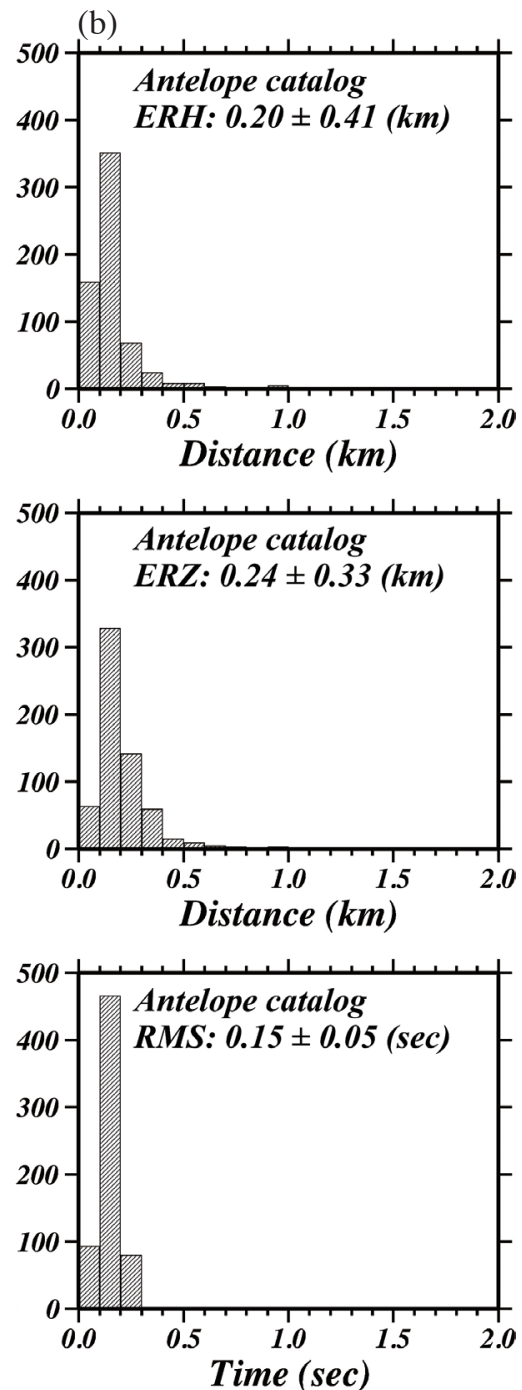

Fig. 5. Histograms of statistic event location errors from (a) the CWBSN catalog and (b) the preliminary Antelope catalog from this study. Panels are arranged in three rows corresponding to distance errors in the horizontal plane (ERH), distance errors in the vertical plane (ERZ), and the averaged root-mean-square errors (RMS) of travel time residuals, respectively. 
and RMS are listed in Table 2. For the Antelope catalog, an estimated $91 \%$ of the ERH and $83 \%$ of the ERZ are concentrated between $0-0.3 \mathrm{~km}$. The small averaged errors and deviations imply that both the epicenter and the depth in this catalog are well constrained. Based on its smaller errors and approximate RMS, we suggest that the preliminary catalog determined using the Antelope software can provide high spatial aftershock distribution resolution for the 4 March 2008 Taoyuan earthquake sequence. Despite the limited number of CWBSN near-source stations used to locate this earthquake sequence, the earthquake location errors from the CWBSN were less than $0.75 \mathrm{~km}$ in this region and may be the same for other instruments on the island of Taiwan. One reason for the strength of the results from the CWBSN instruments may be the experience of this group in arranging regional networks and monitoring local earthquakes from the Taiwan region.

For a moderate earthquake, the earthquake moment tensor can be well resolved using seismic waveform inversion based on the point source assumption (Zhu and Helmberger 1996). However, the fault slip area is small in size and there are limited waveform discrepancies to determine the rupture plane. The fault rupture plane of a moderate earthquake is also difficult to resolve from the aftershock distribution, which are themselves located using a regional seismic network. Hence, the detailed rupture processes for moderate events are rarely reported. However, a few previous studies reported on complex faulting processes for moderate events. Mori (1996) studied the foreshock $\left(\mathrm{M}_{\mathrm{w}} 4.3\right)$ source processes of the 1992 Joshua Tree Earthquake $\left(\mathrm{M}_{\mathrm{w}} 6.1\right)$ and concluded that a high static stress drop in this foreshock, from a rupture, propagated toward the hypocenter of the main shock. Yang et al. (2009) relocated aftershocks and determined the fault plane of the 18 April 2008 Mount Carmel, Illinois earthquake. They concluded that the aftershock distribution was consistent with focal mechanism solutions for the main shock and the four largest aftershocks. Allmann and Shearer (2007) identified a high-frequency secondary event buried on the rupture plane of the 2004 Parkfield earthquake and concluded that this event was located near the edge of a large asperity. It is recognized that detailed observation and analysis of moderate events should be helpful for understanding the fine structure of source ruptures and the micro-behaviors of earthquake sources physics (Mori 1996; Yang et al. 2009). Such analyses can provide significant information relevant to debates on source scaling, stress drop and initial phases. The relocation of dense near-source array observations in this study enhanced the spatial resolution of the aftershock distribution for the Taoyuan earthquake. This study is an example of moderate earthquake detailed aftershock analysis. It provides an opportunity to study the detailed rupture processes and stress distributions for moderate earthquakes in the future.

Liu et al. (2003) proposed that most aftershocks proba- bly do not occur directly on the rupture plane and that structural complexity appears to correlate with a greater relative abundance of small earthquakes. Analyses from the present study indicate that the aftershock distribution of the 4 March 2008 , Taoyuan earthquake is consistent with focal mechanism solutions for the main shock, foreshock and the largest aftershock, and occur along the same fault plane. Furthermore, Fig. 6 shows the epicenter distribution and a profile of the hypocenters along the $\mathrm{N} 53^{\circ} \mathrm{W}$ direction obtained from the hypoDD relocation. The distribution of relocated aftershocks along the profile shows a dip of $\sim 45^{\circ} \mathrm{SE}$. This result matches with one of the focal mechanism nodal planes determined by BATS $\left(\right.$ strike $=37^{\circ}$, dip $=48^{\circ}$, and rake $=96^{\circ}$ ). We suggest that this inferred plane (strike $\mathrm{N} 37^{\circ} \mathrm{E}$ and dip $45^{\circ} \mathrm{SE}$ ) is the fault plane of the main shock. In this region only the Ne-In Fault is identified as an active fault and its rupture has been proposed as a candidate for this event. The $\mathrm{Ne}-\mathrm{In}$ Fault connects with the northern extension of the Chishan Fault, an oblique reverse fault with a NE - SW strike (Lin et al. 2009). We suggest that the faulting on the northern extension of the regional major active fault, the Chishan Fault, may have caused the Taoyuan earthquake sequence. However, in the profile of Fig. 6 we plotted a solid line with a dip angle of $45^{\circ}$ through the main shock hypocenter to the ground surface. This line does not match the surface location of the Ne-In Fault but falls to its west. The mismatch may be due to a bending of the Ne-In Fault plane (dashed line in the figure) near the surface.

\section{CONCLUSIONS}

The fault orientation of the 4 March 2008 Taoyuan earthquake has been successfully imaged based on dense near-source seismic observations. The aftershocks delineate a clear fault with a strike of $\mathrm{N} 37^{\circ} \mathrm{E}$ and a dip of $45^{\circ} \mathrm{SE}$, which agree with the focal mechanisms determined using moment tensor inversion. Based on the inferred fault plane and a regional active fault survey, we suggest that this earthquake sequence can be attributed to faulting related to the Ne-In Fault, a northern extension of the Chishan Fault. Using waveform cross-correlation and double-difference earthquake location techniques, this earthquake sequence has been well resolved using dense seismic observations.

Table 2. Error estimates of the averaged ERH, ERZ, and RMS from the CWBSN catalog and the Antelope preliminary cata$\log$ for the Taoyuan earthquake sequence.

\begin{tabular}{ccc}
\hline & CWBSN catalog & Antelope catalog \\
\hline ERH $(\mathrm{km})$ & $0.62 \pm 0.52$ & $0.20 \pm 0.41$ \\
ERZ $(\mathrm{km})$ & $0.73 \pm 0.48$ & $0.24 \pm 0.33$ \\
RMS $(\mathrm{sec})$ & $0.13 \pm 0.06$ & $0.15 \pm 0.05$ \\
\hline
\end{tabular}



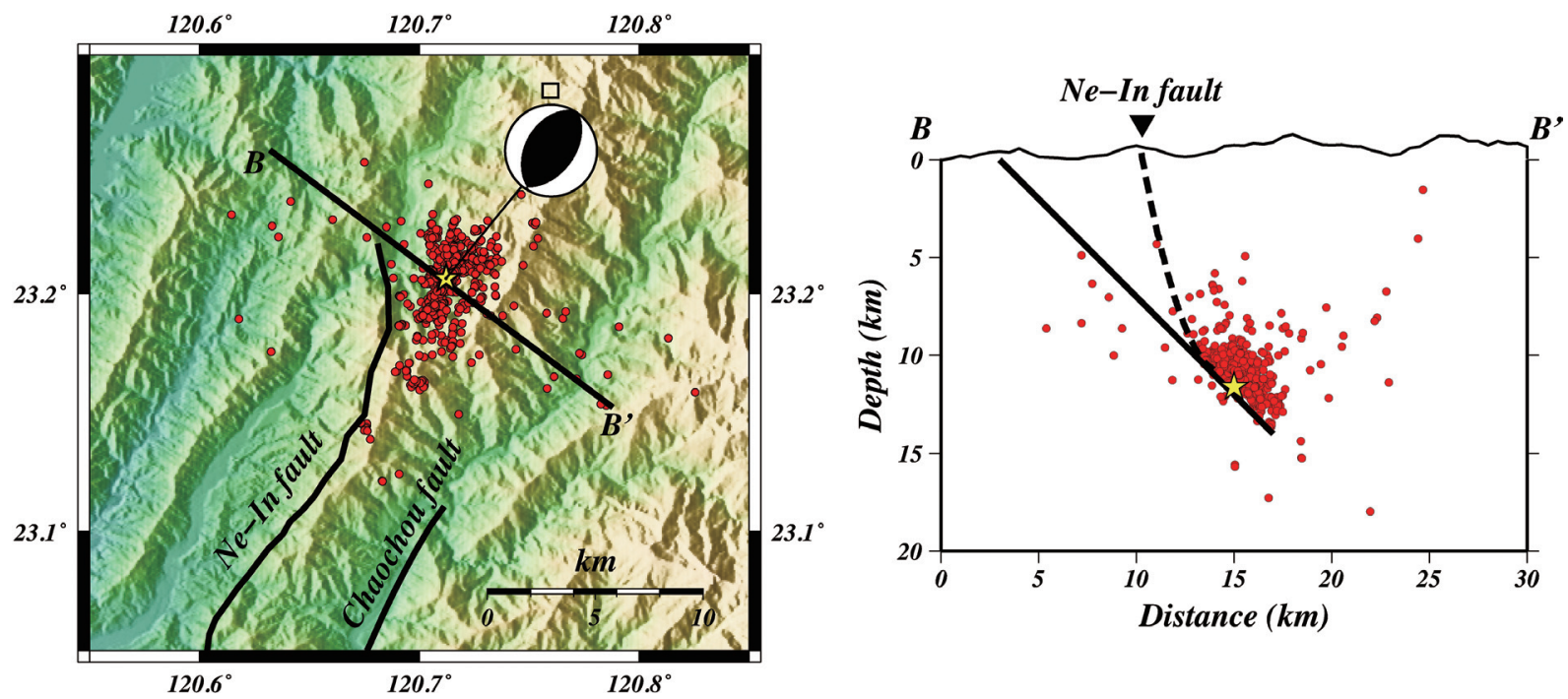

Fig. 6. Map of regional active faults and the epicenter distribution of the 4 March 2008 Taoyuan earthquake sequence (left panel), and a profile of the hypocenters along the cross-section B - B' defined in Fig. 2 (right panel). Plotted events were retrieved from the hypoDD catalog from this study. Thick black lines in the left panel are active faults in the region (Lin et al.2009). In the right panel, the solid thick line indicates the extrapolation of the rupture fault plane to the free surface and the dashed line represents a curved segment to connect the rupture fault plane to the surface fault trace.

Although moderate in size, this earthquake revealed a complex aftershock distribution, which included several clusters and a seismic gap beneath the main shock hypocenter. This is suggestive of complex source faulting processes. This dense near-source seismic analysis provides an opportunity to study the detailed rupture processes of moderate events in the future.

Acknowledgments The authors thank the Central Weather Bureau and the Institute of Earth Sciences, Academia Sinica for logistical support and for making the data used in this study available. They also thank Prof. Hiroo Kanamori and Bertrand Delouis for useful comments and valuable discussions. GMT software (Wessel and Smith 1995) was used to create some of the figures. Academia Sinica supported this study under grant AS-102-SS-A09, and the National Science Council of Taiwan under grants NSC-992116-M-001-022, NSC-100-2116-M-001-019, and NSC101-2116-M-001-033.

\section{REFERENCES}

Allmann, B. P. and P. M. Shearer, 2007: A high-frequency secondary event during the 2004 Parkfield earthquake. Science, 318, 1279-1283, doi: 10.1126/science.1146537. [Link]

Antelope User Group, 2014: Available at http://antelopeusersgroup.org/.

Bannister, S., C. Thurber, and J. Louie, 2006: Detailed fault structure highlighted by finely relocated aftershocks, Arthur's Pass, New Zealand. Geophys. Res. Lett., 33,
L18315, doi: 10.1029/2006GL027462. [Link]

Chen, Y. L., 1995: Three-dimensional velocity structure and kinematic analysis in the Taiwan area. Master Thesis, National Central University, Jungli, Taiwan.

Flinn, E. A., 1965: Confidence regions and error determinations for seismic event location. Rev. Geophys., 3, 157185, doi: 10.1029/RG003i001p00157. [Link]

Klein, F. W., 1978: Hypocenter location program HYPOINVERSE: Part I. Users guide to versions 1, 2, 3, and 4. US Geological Survey, Open-File Report 78-694, $113 \mathrm{pp}$.

Lahr, J. C., 1989: HYPOELLIPSE/version 2.0 (super): A computer program for determining local earthquake hypocentral parameters, magnitude, and first motion pattern. US Geological Survey, Open-File Report OF 89-0116, $81 \mathrm{pp}$

Lee, W. H. K. and J. C. Lahr, 1975: HYPO71 (revised): A computer program for determining hypocenter, magnitude, and first motion patterns of local earthquakes. US Geological Survey, Open-File Report, 75-311.

Lin, C. H., 2010: Temporal b-value variations through out a seismic faulting process: The 2008 Taoyuan earthquake in Taiwan. Terr. Atmos. Ocean. Sci., 21, 229234, doi: 10.3319/TAO.2009.02.09.01(T). [Link]

Lin, C. W., W. S. Chen, Y. C. Liu, and P. T. Chen, 2009: Active faults of Eastern and Southern Taiwan. Spec. Publ. Cent. Geol.Surv., 23, 111-132.

Liu, J., K. Sieh, and E. Hauksson, 2003: A structural interpretation of the aftershock "Cloud" of the $1992 M_{\mathrm{W}} 7.3$ Landers earthquake. Bull. Seismol. Soc. Am., 93, 13331344, doi: 10.1785/0120020060. [Link] 
Mori, J., 1996: Rupture directivity and slip distribution of the $M 4.3$ foreshock to the 1992 Joshua Tree earthquake, Southern California. Bull. Seismol. Soc. Am., 86, 805-810.

Okaya, D., F. Wu, C. Y. Wang, H. Y. Yen, B. S. Huang, L. Brown, and W. T. Liang, 2009: Joint passive/controlled source seismic experiment across Taiwan. Eos, Trans., $A G U, 90,289-290$, doi: 10.1029/2009EO340001. [Link]

Waldhauser, F. and W. L. Ellsworth, 2000: A doubledifference earthquake location algorithm: Method and application to the northern Hayward Fault, California. Bull. Seismol. Soc. Am., 90, 1353-1368, doi:
10.1785/0120000006. [Link]

Wessel, P. and W. H. F. Smith, 1995: New version of the Generic Mapping Tools released. Eos, Trans., AGU, 76, 329, doi: 10.1029/95EO00198. [Link]

Yang, H., L. Zhu, and R. Chu, 2009: Fault-plane determination of the 18 April 2008 Mount Carmel, Illinois, earthquake by detecting and relocating aftershocks. Bull. Seismol. Soc. Am., 99, 3413-3420, doi: 10.1785/0120090038. [Link]

Zhu, L. and D. V. Helmberger, 1996: Advancement in source estimation techniques using broadband regional seismograms. Bull. Seismol. Soc. Am., 86, 1634-1641. 